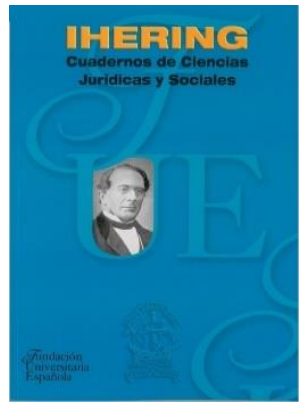

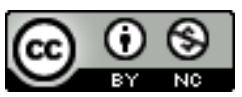

Ihering. Cuadernos de Ciencias Jurídicas y Sociales N. 04

Año: 2021

Publicación del SEMINARIO DE ESTUDIOS EUROPEOS "DIEGO DE MENDOZA" de la Fundación Universitaria Española e-ISSN: 2660-552X DOI: https://doi.org/10.51743/ihering.268

Recibido: 16-11-2021 | Revisado: 21-12-2021 Aceptado: 22-12-2021 | Publicado: 23-12-2021

\title{
LA MONARQUÍA COMO GARANTÍA CONSTITUCIONAL: EL DESEMPEÑO PÚBLICO DE FELIPE VI
}

THE MONARCHY AS A CONSTITUTIONAL GUARANTEE: THE PUBLIC PERFORMANCE OF FELIPE VI

\author{
MIGUEL ARROYO DE LA CRUZ \\ Universidad Rey Juan Carlos
}

\section{RESUMEN}

En la incertidumbre que golpea al Reino de España, los ciudadanos encuentran un salvavidas para la estabilidad y la continuidad histórica de la nación; La monarquía liderada por Felipe VI. En su aún corta y adversa trayectoria de reinado se estudiarán las funciones que tiene atribuidas el monarca como jefe de Estado y su utilidad pública al frente de la institución como garantía y consolidación para el correcto funcionamiento del sistema constitucional e institucional.

\section{Palabras Claves}


Monarquía. Estabilidad. Constitución. Estado de derecho. Legitimidad. Desafío.

\section{ABSTRACT}

In the uncertainty that hits the Kingdom of Spain, the citizens find a lifeline for the stability and historical continuity of the nation; The monarchy led by Felipe VI. In his still short and adverse reign, will be studied the functions attributed to the monarch as head of state and his public utility at the head of the institution as a guarantee and consolidation for the proper functioning of the constitutional and institutional system.

\section{Key Words}

Monarchy. Stability. Constitution. Rule of Law. Legitimacy. Defiance.

\section{ABREVIATURAS}

ETA. Euskadi Ta Askatasuna (País Vasco y Libertad)

BOE. Boletín Oficial del Estado.

LRP. Ley de Reforma Política.

LO. Ley Orgánica.

PCE. Partido Comunista Español.

PNV. Partido Nacionalista Vasco.

CEOE. Confederación Española de Organizaciones Empresariales.

UGT. Unión General de Trabajadores.

Constitución Española. Constitución Española. 
TVE. Televisión Española.

CEE. Comunidad Económica Europea.

OTAN. Organización del Tratado del Atlántico Norte.

SM. Su Majestad.

RAE. Real Academia Española de la Lengua.

PP. Partido Popular.

PSOE. Partido Socialista Obrero Español.

PGE. Presupuestos Generales del Estado.

RRCC. Reyes Católicos.

\section{INTRODUCCIÓN}

En los últimos 5 años, España ha sido testigo de los hitos más relevantes de la Monarquía Española, y de la manera más actual: La monarquía de Felipe VI como garantía constitucional y su desempeño público servidor público, en el que, a través de sus discursos, su ejemplo y sus intervenciones públicas ha logrado cimentar el relevo generacional en la Jefatura del Estado.

Desde hace siglos, incluso hace un milenio, la monarquía siempre ha sido un referente en la historia de España, desde su origen hasta el presente. Fruto de la evolución de los avances sociales, políticos y económicos, la monarquía ha ido evolucionando hasta nuestros días siendo reflejada y detallada en nuestra Carta Magna. Desgraciadamente, bien por desinterés o desconocimiento, algunos sectores de la ciudadanía desconocen la necesidad y la utilidad que tiene nuestra monarquía en el siglo XXI, por lo que se antoja más necesario que nunca dar respuesta e información a la cuestión. En este artículo se analizan la diversidad de funciones y utilidades prácticas y publicas que la constitución otorga al monarca 
como garante y pilar de la estabilidad (social, política y económica), unión y futuro de la nación.

Desde la abdicación de su padre, en 2014, se proclamó a Felipe VI como rey de España ante las Cortes Generales. Todo ello bajo una consigna: "Una monarquía renovada para un tiempo nuevo". El análisis de los acontecimientos que se han ido sucediendo, unido a sus escasos años de reinado, Felipe VI ha optado por renovar la Corona, por necesidad, adaptándose a una nueva realidad, una generación que se habría paso y que demandaba cambios profundos como fruto de una Nueva España.

\section{EL ARTE DE LA TRANSICIÓN BAJO UN ESTANDARTE: LA MONARQUÍA Y EL ESTADO DE DERECHO}

En el siglo XX, mediante la Ley de Sucesión en la Jefatura del Estado de 1947, Franco estableció que el futuro rey de España sería designado por él mismo. Así Don Juan Carlos se convertiría en su sucesor, pero a título de rey. Aceptado por Don Juan Carlos, esto creó un conflicto interno en la casa de Borbón, puesto que los derechos sucesorios correspondían al Conde de Barcelona (Juan de Borbón, que no renunció a sus derechos hasta el 14 de mayo de 1977).

En julio de 1969, Don Juan Carlos I juró las Leyes Fundamentales del Reino y los Principios del Movimiento Nacional. Para sorpresa de muchos, usó esas mismas leyes para impulsar el cambio de régimen y hacer posible la transición de una dictadura a una democracia. Con la muerte de Franco, Don Juan Carlos jura los Principios del Movimiento Nacional y fue proclamado rey por las Cortes Españolas en 1975. A pesar de ello, desde su posición alentó la Ley para la Reforma Política (LRP) que fue apoyada con un 94\%. Este hecho fue la pieza inicial para la transición hacia la democracia.

Don Juan Carlos inició su reinado sin salirse de los cauces de la legalidad franquista, pero ya en su discurso de proclamación en las Cortes se mostró abierto 
a una transformación del sistema político español. De esta forma, su reinado abandonaría el inmovilismo que propugnaba el búnker (que defendía la continuación del franquismo en la figura del rey según lo establecido en la L.O del Estado de 1967 ) y con menciones especiales al ejército, al que aconsejó afrontar el futuro con serenidad y tranquilidad.

La monarquía de Don Juan Carlos I no tardó en encontrarse problemas, empezando por la ratificación como presidente del gobierno de Carlos Arias Navarro que fue amortiguado, en cierta manera, por el nombramiento de Torcuato Fernández Miranda como presidente de las Cortes. También participaron de este gobierno los reformistas franquistas Adolfo Suárez, Manuel Fraga y Martín Villa. En estos casos, los nombramientos les fueron impuestos a Arias Navarro por parte del rey. En el caso de Suárez, fue petición directa de Fernández Miranda. La reforma de las leyes franquistas por parte del gobierno Arias-Fraga iba a ser un fracaso que Suárez aprendería para posteriores derogaciones de esas mismas leyes: todo debería reducirse a una sola modificación: La nueva LRP.

La ley iba a ser el pilar sobre el que se inició la Transición. El ocaso (en pro del cambio de régimen) de las Cortes franquistas tuvo lugar por la votación a favor de esta ley. Pero no fue el único obstáculo, ya que se hubo de convencer a la cúpula militar (fue una de las principales ocupaciones del rey, ganarse al ejército, ello fue posible y así lo dice el mismo Don Juan Carlos I) de la necesidad de esta reforma, a la oposición democrática y se debía producir el desalojo de los franquistas inmovilistas de las instituciones. Esta ley se sometió a referéndum el 15 de diciembre de 1976 y fue aprobada con una amplia mayoría del $91,81 \%$ de los votantes.

Tabla 1.

Resultado del Referéndum sobre el proyecto de Constitución 


\begin{tabular}{lll}
\hline Designación & Resultado & Porcentaje \\
\hline Electores & 26.632 .180 & $100 \%$ \\
Votantes & 17.873 .301 & $67,11 \%$ \\
Votos a favor & 15.706 .078 & $91,81 \%$ \\
Votos en contra & 1.400 .505 & $8,19 \%$ \\
Votos en blanco & 632.902 & $3.54 \%$ \\
Votos nulos & 133.786 & $0,75 \%$ \\
\hline
\end{tabular}

Nota. Recuperado del Congreso de los Diputados. Copyright 2003.

El camino a la Transición continuó con algunos episodios muy graves, como la matanza de los abogados de Atocha. Los acontecimientos se unieron a los continuos atentados de ETA. Los hechos se aceleraban, y el 15 de octubre de 1977 se aprobó la Ley 46/1977 de Amnistía, que establecía la libertad de los presos que aún se encontraban en las cárceles por delitos de motivación política.

La convulsión política se acentuó por la crisis económica de 1974, aún sin abarcada por la prioridad a la Transición. Como consecuencia de ello, Fuentes Quintana y Adolfo Suárez firmaron los Pactos de la Moncloa. Paradigma del mayor consenso político hasta la fecha, se llevaron a cabo mejoras sociales y algunas reformas jurídicas. Este pacto, firmado el 27 de octubre de 1977, logró estabilizar la economía y controlar la inflación y, pero como consecuencia, se aumentó el gasto social (preludio del llamado Estado de Bienestar). Se creó el Círculo de Empresarios y la CEOE. Esto generó conflictividad laboral, hasta que la CEOE y UGT firmaron el Marco Confederal en 1979. 
Como resultado de los avances políticos y jurídicos en España, el momento álgido del reinado de Don Juan Carlos I fue la aprobación de la Constitución Española el 18 de noviembre de 1978, en la que se suprime toda participación política de la Corona y convirtiendo a España en la monarquía parlamentaria de corte occidental que es en la actualidad.

Asentada la monarquía y Juan Carlos I, tuvo que abordar uno de los momentos más graves de su reinado con el intento de Golpe de Estado del teniente coronel Antonio Tejero, el 23 de febrero de 1981. La intervención televisiva del rey Don Juan Carlos I desautorizando el golpe acabó con la conjura, que le granjeó las simpatías de los ciudadanos que le recibieron con desconfianza.

Los gobiernos socialistas, ya terminada la Transición, en 1985 culminaron las negociaciones para el ingreso en la Comunidad Económica Europea (CEE) y el 12 de marzo, Felipe González, gana el referéndum para la entrada en la OTAN con un $52 \%$ de síes. En 1995 se crea el Pacto de Toledo, para dar respuesta a la cuestión de la Seguridad Social. Se reuniría cada 5 años.

Después de 40 años reinando en España y con una nueva generación que necesitaba ser liderada por un relevo generacional, la consecuencia para la abdicación de Don Juan Carlos I se encendió tanto por motivos personales como legales.

\section{LA ABDICACIÓN COMO RESULTADO DE UNA NUEVA ESPAÑA}

La abdicación de un monarca, regulada en el artículo 57.5 Constitución Española, requería en esos momentos que se tramitara en la sombra para evitar cualquier debate innecesario y poder así continuar con la estabilidad de la monarquía a través de los medios constitucionales pertinentes.

Además, se pretendió que la abdicación, sumada a otros factores, fuese una solución o cortafuegos para paralizar el deterioro que estaba sufriendo tanto la monarquía como su propio titular por los escándalos inasumibles que iban saliendo 
a la luz para la sociedad española e iban enterrando los méritos logrados por el propio rey emérito. Sin embargo, ese deterioro no se ha visto completamente reducido a pesar de la dedicación, preparación y ejecución con la que se realizó.

Los motivos se basaron en asuntos políticos y, en menor medida, por asuntos personales (salud del monarca), después de cuatro décadas reinando. Para ello, se obró con rapidez y las circunstancias políticas ayudaron al desarrollo de la misma, en especial, de la mano de Mariano Rajoy y Rubalcaba para la aprobación de una Ley Orgánica que hiciera posible la abdicación con el respaldo de un $85 \%$ (299 votos a favor), la mayoría del Parlamento, seguido de 19 votos en contra y 23 abstenciones.

El 02 de junio de 2014, Don Juan Carlos I abdica en su hijo Felipe, "[...] he decidido poner fin a mi reinado y abdicar la Corona de España, deponiendo en manos del Gobierno y de las Cortes Generales mi magistratura y autoridad para que provean a la efectividad de la sucesión en la Corona conforme a las previsiones constitucionales.", que asumió el cargo como Felipe VI.

Como dicta la Constitución Española, se redactó una Ley Orgánica que aplicara dicha sucesión, que resultó ser la L.O 3/2014 de 18 de junio por la que se hace efectiva la abdicación de S.M el Rey Don Juan Carlos I de Borbón.

No obstante, en las últimas palabras del rey, tienen su explicación como resultado de la modernización de España a nivel nacional e internacional unidas a las nuevas exigencias que deparaba el futuro hacía urgente la renovación de la Corona para afrontar tales desafíos. Y así fue:

"En la forja de ese futuro, una nueva generación reclama con justa causa el papel protagonista, el mismo que correspondió en una coyuntura crucial de nuestra historia a la generación a la que yo pertenezco.

Hoy merece pasar a la primera línea una generación más joven, con nuevas energías, decidida a emprender con determinación las transformaciones y 
reformas que la coyuntura actual está demandando y a afrontar con renovada intensidad y dedicación los desafíos del mañana."

Cumpliendo el rey su último cometido para la continuidad de España y de la monarquía junto con su inherente estabilidad, pasa el testigo a su hijo, el príncipe de Asturias, Felipe: "El Príncipe de Asturias tiene la madurez, la preparación y el sentido de la responsabilidad necesarios para asumir con plenas garantías la Jefatura del Estado y abrir una nueva etapa de esperanza en la que se combinen la experiencia adquirida y el impulso de una nueva generación. Contará para ello, estoy seguro, con el apoyo que siempre tendrá de la Princesa Leticia".

Sin embargo, los cambios que Felipe VI se ha encontrado durante su reinado tuvieron su origen del vacío familiar causado por los problemas con la justicia, unido al desgaste que ha sufrido la Corona junto con los problemas que su padre había dejado por el camino y en la propia institución lo que tendrá como consecuencia un camino más dificultoso para el reinado de Felipe VI.

\section{METODOLOGÍA Y ORDEN CONSTITUCIONAL}

Para abordar de la manera más eficiente el artículo, el enfoque de la investigación y el grueso del análisis de las funciones y utilidad del monarca se desprenderán de la combinación simultánea del estudio de la regulación constitucional de la Corona y de las intervenciones públicas del monarca (Discursos, actos oficiales, etc.).

El desarrollo del artículo irá encaminado a valorar los aspectos objetivos tomando de referencia el contenido de los artículos constitucionales, de la manera más neutral. La constitución de 1978, fruto de la evolución de los diversos acontecimientos que configuraron la necesidad de la misma se desprende, a continuación, un análisis sobre las funciones y papel de la Jefatura del Estado en su desempeño y servicio público. 


\subsection{LA CONSTITUCIÓN DE 1978. LA FIGURA DE UN REY PLENAMENTE CONSTITUIDO}

La Monarquía, institución longeva caracterizada por estar al frente de la misma un monarca, una figura histórica, que constituye parte de nuestro pasado, presente y futuro. Como consecuencia, España fue formada como Estado, incluso como un Imperio, por reyes predecesores al actual y fue moldeada por los siguientes que ciñeron Corona en nuestro país, si bien es cierto que con dos intentos de formar una república que fracasó, hasta nuestros días.

No comprender el alcance de la figura del rey en España, coloca a los ciudadanos en la situación de no entender la historia de su propio país, puesto que no se puede pretender avanzar hacia el futuro sino se conoce el pasado, así lo decía el escritor y miembro de la Real Academia Española (R.A.E) Arturo Pérez Reverte "[...] Perder la memoria es perder España", y es imposible que la monarquía avance y sea fortalecida si no se conoce.

El Príncipe de Asturias en el Discurso de entrega Premio Príncipe de Viana, ya decía que; "[..] el mejor conocimiento del pasado favorece que las sociedades avancen con paso firme hacia el futuro, del mismo modo que los árboles precisan de recias raíces afianzadas en la tierra para poder crecer con más fuerza".

Por lo tanto, el objetivo de la presente investigación es estudiar la posición del monarca en la constitución, su alcance, legitimidad y funciones además de otras que comentaremos. En base a lo esgrimido anteriormente, la forma política del Estado español se constituye como una monarquía parlamentaria, como así lo establece el artículo 1 de la Constitución Española. En la norma suprema del ordenamiento jurídico, se establece un rey que tiene muy tasadas sus funciones y competencias, además de su papel en la sociedad. En la Constitución, la Corona es una institución que tiene carácter histórico y permanente, siendo uno de los poderes que están constitucionalmente establecidos en la Carta Magna, cuya naturaleza es única; el poder del Rey es sui generis (algo único en su especie)

Attribution-NonCommercial 4.0 International (CC BY-NC 4.0). 
porque la Corona es algo más que un poder constitucional, que no forma parte del gobierno, pero sí del Estado.

\subsection{LA CONSTITUCIÓN DE 1978. LAS FUNCIONES CONSTITUCIONALES DEL REY}

En el título II de la Constitución se desarrollan las bases en lo relativo a la Corona, en concreto, en los artículos 56 y siguientes, dividiéndose los diferentes temas en partes, a saber: La figura del rey y sus funciones, la sucesión a la Corona, la regencia y la tutela y, por último, el refrendo.

En la constitución, el artículo 56.1 Constitución Española, establece que el rey ostenta la Jefatura del Estado (la más alta representación del Estado), baluarte y símbolo de la unidad de la nación. Se enumeran las funciones que le corresponden al Monarca, como lo son moderar, arbitrar y representar al Estado a nivel internacional y ejercer las funciones que le atribuyan la constitución y las leyes. $\mathrm{Al}$ moderar y arbitrar, se refiere al funcionamiento regular de las instituciones, ostentando, como es lógico, una posición imparcial al respecto y velando por su funcionamiento adecuado. Un claro ejemplo de ello sería las sesiones de investidura a presidente del gobierno y las reuniones con los candidatos, en las cuales el rey modera y arbitra el correcto funcionamiento para la consecución de un gobierno.

Seguido de ello, en artículo 56.2 de la Constitución Española, se hace referencia a los títulos del Rey. En el último párrafo se establecen dos cuestiones de especial trascendencia; su inviolabilidad y su irresponsabilidad, nada nuevo en las monarquías, aunque tampoco lo es en las Repúblicas. El apartado 3 del artículo 56 de la Constitución Española ha sido muy sometido a debate, la inviolabilidad e irresponsabilidad del rey, es definida por la R.A.E como "la Prerrogativa en virtud de la cual el rey no está sujeto a responsabilidad". Una posible pregunta que podrán hacerse los lectores podría ser; ¿La inviolabilidad o Irresponsabilidad del rey se extienden a sus propios actos personales o solo a los puramente institucionales? Para ello, en virtud de la R.A.E, no se hace ningún tipo de diferenciación entre los 
actos personales o institucionales. Se entiende, por un lado, que la constitución se refiere principalmente a los actos y funciones que expresamente le otorga la constitución y las leyes. Sin embargo, por otro lado, al tener un carácter esencialmente público, siendo la cara visible de la institución monárquica y ejemplo de la misma para la propia sociedad, derivaría en que los actos personales también podrían dar lugar a ningún tipo de responsabilidad, véase al propio rey emérito Don Juan Carlos I, cuando se fue a cazar a Botsuana o los "regalos o presentes" que recibió del rey de Arabia Saudí.

Sin embargo, los actos del Rey, tanto fuera como dentro de la institución monárquica, siempre serán tenidos en cuenta por la propia sociedad. Por ello, tanto civil como penalmente, no se puede perseguir al Monarca, sin embargo, no significa que no se pueda someter a juicio a la Familia Real, un claro ejemplo de ello y actual es el juicio a Iñaki Urdangarin, esposo de la Infanta Cristina de Borbón.

Respecto a los actos del rey, deben ser refrendados bien por el presidente del gobierno o por el ministro correspondiente, o incluso por el presidente del congreso de los diputados en el supuesto del artículo 99.1 Constitución Española. El rey no puede negarse a refrendar tales actos, ni a cuestionarlos, no se puede obviar que es una figura que es ajena al gobierno, pero no al Estado. El refrendo de los actos del rey del artículo 56.3 Constitución Española, son las obligaciones que asume el monarca y el cumplimiento de las mismas como rey. Sin embargo, están exentas de las obligaciones del refrendo los actos del Rey las cuestiones relativas al gobierno de la Casa Real, artículo 65.2 Constitución Española.

Respecto al artículo 61.1 de la Constitución Española, el rey no es proclamado por las Cortes Generales debido a que la sucesión es automática a la Jefatura del Estado, sino que es proclamado ante las Cortes, dando lugar a un acto constitutivo propio de la Monarquía con el consiguiente juramento en la proclamación del rey ante las Cortes Generales. Es un acto único y de especial relevancia puesto que se adquiere por parte del Rey un compromiso de por vida de; fidelidad, lealtad, buen desempeño de las funciones, hacer guardar y cumplir la 
Constitución, etc. Asimismo, se vuelve a reafirmar el carácter parlamentario de la Monarquía, propia de nuestra sociedad actual, en la que el Rey se compromete a someterse a la ley y la constitución.

Del mismo modo, el artículo 61.2 de la Constitución Española, establece el juramento que han de prestar tanto el príncipe heredero al alcanzar la mayoría de edad, así como el regente o regentes que al hacerse cargo de las funciones debían de prestar el mismo juramento. Un ejemplo de ello es el Juramento que desempeñó el Príncipe Felipe ante las Cortes Generales el 30 de enero de 1986.

En lo relativo a las funciones del Rey, el artículo 62 de la Constitución Española realiza una enumeración de las mismas, no olvidemos que se tratan de funciones, no de competencias o poderes, dado que expresamente no se hace alusión a ello, de ahí que se refiera a términos como "Corresponde al Rey". No obstante, también ostenta otras funciones como jefe de Estado, como la de moderar y arbitrar el correcto funcionamiento de las instituciones, ostentar la más alta representación del Estado en las relaciones internacionales, artículo 56 Constitución Española. Así mismo, es el baluarte de la unidad del Estado, no el centro político.

El rey al no tener poder para legislar, se le reconoce la facultad de sancionar y promulgar leyes "[...] como función complementaria, integrada en un acto complejo donde intervienen diversas voluntades (iniciativa del Gobierno, deliberación, y aprobación del Parlamento) a las que el Soberano no puede oponerse. Así la sanción real es una fórmula certificante de que la Ley ha sido aprobada por el Parlamento. [...]”. Es una función que está caracterizada porque no tiene contenido real, es decir, el rey no se puede oponer a ello dado que los actos provienen de las Cortes Generales. En el caso de que se opusiese el rey a promulgar una ley, ya sea porque es inconstitucional o lo considere inmoral, tendría lugar la abdicación.

Al rey también le corresponde Convocar y disolver las Cortes Generales, así como convocar elecciones según lo establecido el artículo 62 b) Constitución Española. El rey tiene el deber, como monarca parlamentario, de dar cumplimiento 
a dicho precepto por exigencia constitucional mediante el correspondiente refrendo. Siendo el presidente del Gobierno el que lo proponga, previa consulta a al Consejo de ministros, siendo finalmente decretada por el propio rey, artículo 115.1 Constitución Española.

Un ejemplo de su capacidad de moderación e intervención sería, desde su proclamación como monarca en 2014, se han celebrado cuatro Elecciones Generales (2015, 2016, 2019-abril, 2019-noviembre). Cuatro en menos de cuatro años. Ello es un reflejo de la gran inestabilidad política que impera en España. Evidentemente, la falta de Gobierno no sólo se debe a la inestabilidad política sino también a la aparición de nuevas formaciones políticas (ruptura del Bipartidismo), no hizo más que dispersar aún más el voto, forzando así a los nuevos gobiernos a formar alianzas y pactos para la investidura. De ahí, se desprende a la vista de los resultados electorales que la dificultad de llegar a consensos entre los partidos ha dado lugar a la propia inestabilidad política y la reiterada repetición de las Elecciones Generales teniendo como resultado un malestar social, político y económico generalizado.

En estas cuatro elecciones Generales, al Rey Felipe VI le ha correspondido realizar las correspondientes rondas de consultas con los candidatos presentados a la presidencia del Gobierno de España. De entre los candidatos, normalmente el que haya obtenido más votos en las elecciones, el rey propone a uno como candidato a la presidencia del gobierno, artículo 62 d) Constitución Española. De estos hechos, se desprenden varias funciones del monarca, que debe velar, moderar y arbitrar para el correcto funcionamiento de las instituciones públicas con la finalidad de evitar la paralización o estancamiento de éstas en perjuicio de los ciudadanos. Además de ello, encuentra su fundamento en el artículo 99.1 de la Constitución Española, seguido de ello, deberá recibir el correspondiente apoyo de la cámara el candidato para poder ser investido presidente del gobierno, artículo 99.2 Constitución Española. 
Respecto al nombramiento y separación de los miembros del gobierno a propuesta de su presidente, artículo 62 e) Constitución Española. Destaca en este aspecto que el monarca no ostenta de una libertad absoluta para nombrar y separar a los miembros del gobierno, ello encuentra su parecido con el artículo 100 de la Constitución Española, sino que tal función vendrá a consecuencia de la propuesta del presidente del gobierno. Es preciso insistir en que el monarca no es solo constitucionalista sino también parlamentario, en el que el poder ejecutivo lo ostenta el gobierno.

Por otro lado, el monarca tiene el deber de expedir los decretos acordados en el Consejo de ministros, así como conferir empleos civiles y militares y conceder honores y distinciones con arreglo a las leyes, artículo 62 f) Constitución Española. Como consecuencia de ello, no ostenta una posición de poder cuestionar tales nombramientos puesto que son el resultado de las normas aprobadas por el Consejo de ministros, es decir, el monarca refrenda los actos de éstos últimos mediante su propia firma corroborando tales nombramientos o decretos. Además de ello, con previa consulta al Gobierno, conferirá los empleos y honores antes mencionados con arreglo a las leyes.

Felipe VI, como jefe del Estado, deberá ser informado de los asuntos de Estado y presidir, a estos efectos, el Consejo de ministros a petición del presidente del Gobierno, artículo $62 \mathrm{~g}$ ). Son situaciones excepcionales u ocasionales en el que el monarca ostenta la presidencia del Consejo de ministros para poder ser informado de las cuestiones de especial relevancia política, tanto por parte del propio presidente, como con los representantes de las fuerzas políticas y también por los líderes autonómicos. Cabe destacar que esta función tiene una naturaleza relacional, entre el Rey y las Cortes Generales.

También ostenta, al igual que su padre Don Juan Carlos, el mando supremo de las Fuerzas Armadas, artículo 62 h) Constitución Española. Tiene su razón de ser en las atribuciones que en su momento tuvo el Rey Emérito, no obstante, en la vigente Constitución el monarca podrá realizar tales funciones en materia de 
influencia, pero sin tener un poder efectivo sobre las fuerzas armadas. Ello quiere decir que, al ser una monarquía parlamentaria donde el monarca está sometido a la ley y a la Constitución, corresponderá así en primera instancia la dirección de la administración militar y la defensa del estado al propio gobierno tal y como se encuentra establecido en el artículo 97 de la Constitución Española.

No obstante, un ejemplo de la influencia que puede tener el Rey en las Fuerzas Armadas, el más paradigmático es el Discurso del 23 de febrero de 1981 en el que destacó en lo relativo a las órdenes que remite el monarca a las Fuerzas Armadas en defensa de la constitución. No será ello objeto de estudio en este momento, pero más adelante se establecerán las analogías pertinentes entre el Discurso del 23-F y el Discurso del 03-O. De ahí, la importancia de las palabras del monarca, tanto de cara ámbito civil y militar, reclamando serenidad y la plena defensa de la constitución frente a los ataques externos e internos.

Otra de las funciones del Rey, es el ejercer el derecho de gracia con arreglo a la ley, que no podrá autorizar indultos generales, artículo 62 i) Constitución Española. Un caso bastante actual, dado que en esencia quien propone los indultos es el gobierno-poder ejecutivo y el monarca quien le da plena validez en virtud de la constitución. En las últimas semanas, se está barajando la opción real de concederse los indultos a los condenados por el procés, a pesar del informe negativo del tribunal supremo a la concesión de los mismos. Una acción que pondría a Felipe VI en una situación compleja puesto que después de su intervención pública el 03 de octubre de 2017 y su reiterada defensa de la constitución y la llamada a la depuración de responsabilidades podrían tener como resultado la pérdida de credibilidad y firmeza que ostenta la institución monárquica. Ello tiene estrecha relación puesto que los indultos, además de ser un tema jurídico, encuentra su vínculo más estrecho con el ámbito político.

El objetivo de tal cuestión parece venir respaldado por una estrategia de los propios partidos independentistas para desacreditar al principal obstáculo y símbolo nacional para alcanzar tales pretensiones de ruptura; la monarquía, dado que es el 
pilar que sustenta la nación, la unidad y la historia de España. Felipe VI, una vez más, en estos años tan difíciles de reinado y con un apoyo cada vez más escaso de los partidos políticos deberá dar respuesta a este problema desde la legalidad, la firmeza y serenidad propias de su línea de reinado.

Respecto a los actos del Rey, artículo 64.1 de la Constitución Española, carecerán de validez sin dicho refrendo, salvo lo establecido en el artículo 65.2. El monarca no tiene la facultad de la toma de decisiones, sin embargo, modera, arbitra y es símbolo de la nación, "[...] con su firma, perfecciona determinados actos políticos de gobierno convirtiéndolos en actos de Estado." Dichos actos deben provenir del correspondiente órgano refrendante, como lo son; el presidente del Gobierno, el ministro o el presidente del Congreso. Éstos últimos complementan los actos del monarca pues es una exigencia para la validez o existencia de dichos actos. El Rey, al ser sus actos refrendados, evita así su responsabilidad como jefe de Estado, recayendo la misma sobre los propios refrendantes, artículo 64.2 Constitución Española.

Es una característica esencial de la monarquía parlamentaria que los actos del rey sean refrendados, sometidos a la ley y a la constitución, donde el monarca no desempeña ningún papel en los poderes ejecutivos, pero siendo necesario su firma para dar cumplimiento a los mismos. Una excepción al refrendo de los actos del monarca, se le otorga al monarca un cierto margen bajo la consigna "libremente", según el artículo 65.2 de la Constitución Española al determinar que el rey podrá nombrar y relevar a los miembros civiles y militares de su Casa libremente sin ningún tipo de refrendo.

Respecto a la Casa Real, su sostenimiento al igual que el de la Familia Real, según el artículo 65.1 de la Constitución Española, el Rey recibe las consignaciones monetarias a través de los Presupuestos Generales del Estado (PGE) que se renuevan anualmente. Nuevamente, se le otorga al monarca total libertad para administrar los presupuestos, evidentemente la mayor parte de los mismos van 
destinados a su labor como jefe de Estado, reuniones con líderes políticos de otros Estados, etc.

En los últimos PGE se otorgó a la Casa Real de una designación de alrededor de 8 millones de euros. Aquí cabe hacer una mención especial en lo relativo al coste económico, puesto que nuestra monarquía es una de las que menos coste supone al Estado en comparación con las partidas anuales que reciben otras Casas Reales en Europa.

\section{Figura 1.}

Coste comparativo de las Monarquías Europeas.

\section{¿Cuánto cuestan las monarquías europeas?}

Asignación directa por ciudadano al año (último dato disponible, 2017-2020)*

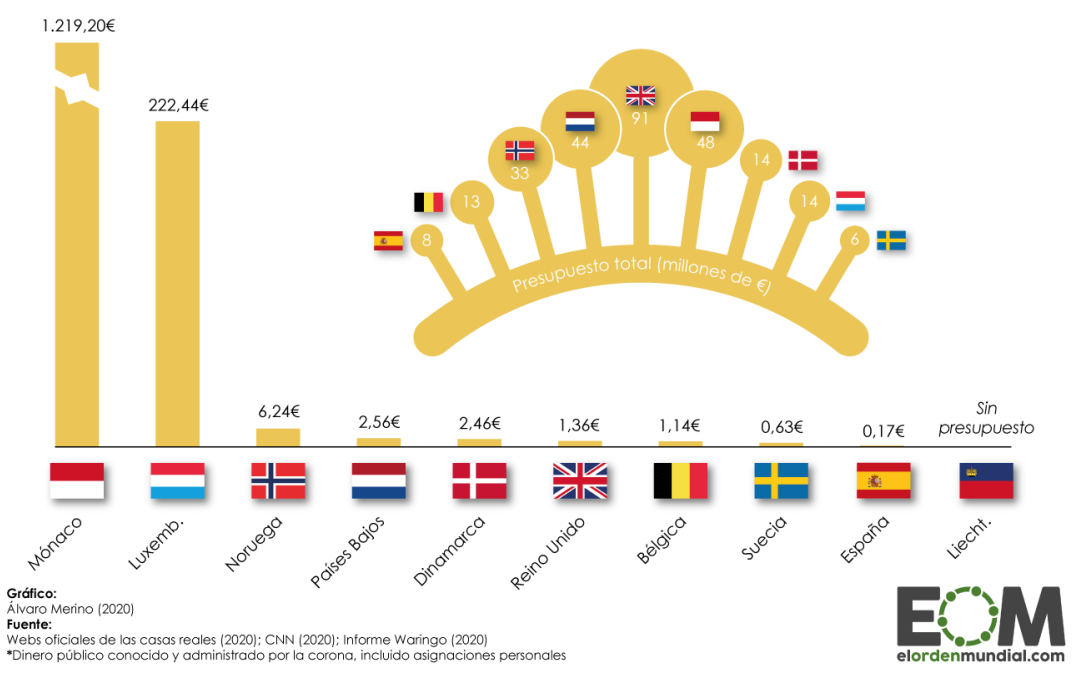

Nota. El gráfico representa una comparativa a nivel europeo sobre las monarquías existentes y su peso económico en los diferentes países junto con la media por ciudadano para sostener económicamente a la institución. Recuperado de Webs oficiales de las casas reales (2020); CNN (2020); Informe Waringo (2020)

Sin embargo, en España, la asignación que reciben los reyes del Gobierno en los PGE no incluye todo el aparato logístico de funcionamiento de la Casa Real, 
véase los sueldos de sus funcionarios, sufragados por el Ministerio de Hacienda, así como el mantenimiento del Patrimonio Nacional, del cual podrá beneficiarse el Rey y los miembros de la Familia Real para su uso y servicio.

Analizada la figura y el desempeño público del rey en la constitución de 1978, actualmente, el orden constitucional se ha visto alterado o desafiado por las pretensiones rupturistas de un sector de la ciudadanía con la consiguiente postura que ha adoptado el rey en la defensa y la promoción de dicho orden, tomando de referente a su padre.

Para la ciudadanía española, los líderes políticos, y en última instancia para el Rey Felipe VI, la preservación, mantenimiento y evolución del orden constitucional se antojaba, más que nunca, necesario. Estos deberes vienen dados tanto por los retos y desafíos que nos afectan desde fuera de España, como los que se producen desde dentro del país. Estar a la altura de las nuevas demandas sociales que emergían tan rápido y tan versátiles en nuestro tiempo es un deber cuya omisión conllevaría al ocaso de una institución histórica y necesaria.

El orden constitucional es el pilar por el cual se han podido solventar las diferencias que parecían tan insalvables y los retos que a priori eran imposibles abordar. Actualmente, se pretende que la monarquía siga siendo fuente de inspiración y estabilidad para la sociedad, una institución de trabajo mutuo que ahonde en la convivencia entre los ciudadanos, respetando los principios fundamentales y libertades públicas de la constitución.

La preservación de dicho orden se refleja también en las palabras que pronunció Felipe VI en su discurso de proclamación como rey de España:

"La independencia de la Corona, su neutralidad política y su vocación integradora ante las diferentes opciones ideológicas, le permiten contribuir a la estabilidad de nuestro sistema político, facilitar el equilibrio con los demás órganos constitucionales y territoriales, favorecer el ordenado funcionamiento del Estado y ser cauce para la cohesión entre los españoles. Todos ellos, valores 
políticos esenciales para la convivencia, para la organización y desarrollo de nuestra vida colectiva."

\section{ACTUALIDAD Y VIGENCIA DE LA CONSTITUCIÓN}

\subsection{CUARENTA AÑOS DEL CONSENSO DE 1978. SU FRAGILIDAD Y NECECIDAD DE DEFENSA}

La constitución de 1978 fue fruto del consenso de partidos muy diferentes y con sentido de estado. Actualmente, la falta de confianza de los ciudadanos en las instituciones públicas se une a las voces que piden una reforma constitucional, que responda a los obstáculos que afronta tanto España como Felipe VI: la crisis económica, el paro, la convivencia en Cataluña y España, el asunto sucesorio, la ley Electoral, desigualdades territoriales, la reforma del ejército, etc.

Como resultado, Felipe VI no solo tuvo que comenzar su reinado con los problemas heredados, sino también los que iban a acontecer más adelante como la inestabilidad política, cuestionamiento de la legitimidad de la monarquía y de la Constitución por ciertos sectores de la sociedad, escándalos en la familia real, la pandemia del Covid-19, entre otros. "El rey tiene dos grandes objetivos [...]: la consolidación de la Monarquía y la unión de las dos Españas." El último término se aborda en lo referente a la polarización que se da cada vez más en la ciudadanía en el ámbito político, pues Felipe VI se ha comprometido a ser el rey de todos los españoles.

\subsection{LA CORONA Y LA LEY EN DEFENSA DE LA CONSTITUCIÓN FRENTE AL GOBIERNO}

La embestida más contundente contra Felipe VI y su reinado llegaría desde Cataluña. Los hechos ocurridos en 2017 dieron la vuelta tanto a nivel nacional como internacional en nuestra joven democracia. Los hechos fueron llevados a cabo con el desarrollo de una narrativa victimista y un despliegue operativo de propaganda y 
manipulación, ejecutados por los partidos independentistas y el apoyo de ciertos sectores de la ciudadanía catalana, y ello se sumaba a la inacción del gobierno.

El 9 de junio de 2017, se anunció la aprobación en el Diario oficial de la Generalitat de Cataluña la Ley 19/2017 del referéndum de autodeterminación de Cataluña , aprobada en el mismo Parlamento Catalán la cual propugnaba la celebración de un referéndum sobre la independencia de Cataluña fundamentándose en la validez y legitimidad de los resultados autonómicos de anteriores años, en concreto de 2015 donde ganó "Junts pel Sí" de Arthur Mas y Carles Puigdemont, junto con la colaboración de más partidos proindependentistas.

La Ley aprobada sobre la autodeterminación de Cataluña fue tumbada al día siguiente por el propio Tribunal Constitucional, a petición del Gobierno, al considerarla inconstitucional. Fragmentada la sociedad y haciéndose más clara la división social por temas políticos e identitarios, se tensó y forzó la situación con un hito histórico en la Historia de España. El 01 de octubre de 2017 se convocó unilateralmente por parte del Gobierno Catalán un referéndum sobre la independencia de Cataluña.

El resultado del 1-0 tuvo como consecuencia, la implantación de urnas ilegales, las cargas policiales, entre otros. Ese mismo día se conoció el resultado de las urnas con un $90,18 \%$ a favor de la independencia, a pesar de que hubo muchas dudas con el desarrollo de la votación y el contraste de los datos, con una participación del 43,03\% lo que llevó al Parlamento Catalán a aprobar la Ley de Transitoriedad Jurídica que apoyaba el camino para establecer una posible constitución de una República Catalana y que inmediatamente fue suspendida por el Tribunal Constitucional.

El ambiente y la tensión en la sociedad española era constatable ante la deriva de los acontecimientos y la permisividad del entonces gobierno de Mariano Rajoy. Las fuerzas de la autoridad no tenían ninguna capacidad de reacción y no se proponía ninguna solución política (ni tampoco por parte de la oposición) al 
problema desencadenado. Ante las circunstancias excepcionales del momento, se filtró que el rey iba a dirigirse a todos los españoles.

Como consecuencia de la situación tan extrema que estaba viviendo la sociedad española seguido de la falta de respuesta de las instituciones, el 03 de octubre de 2017, unos días después del referéndum ilegal, el rey Felipe VI se dirigió por la noche a todos los españoles y, en particular, a los catalanes.

El 03 de octubre de 2017, es el hito más relevante del reinado de Felipe VI, con un discurso en el que toma partido, e incluso, se pone en contradicción con algunas de las posiciones representadas de ciertos partidos políticos en el congreso de los diputados. La situación tan alarmante de Cataluña tuvo como resultado que el rey se posicionase fuera de la neutralidad política como jefe de Estado en defensa del orden constitucional y como garante de la estabilidad que encarna así la monarquía en un Estado de derecho.

La intervención de Felipe VI arrojó ciertas similitudes o analogías con el discurso del intento de Golpe de Estado del 23 de febrero de 1981, que reafirmó a su padre, Don Juan Carlos, como rey y cimentando a la monarquía sobre una base sólida. Ambos discursos, si bien fueron en distintas épocas y en circunstancias diferentes, guardan ciertas similitudes, su intervención pública está fundamentada por las circunstancias tan extraordinarias y tan graves que estaban viviendo los españoles en plena democracia. Un ejemplo de esas analogías es:

Juan Carlos I; "Al dirigirme a todos los españoles, con brevedad y concisión, en las circunstancias extraordinarias que en estos momentos estamos viviendo, pido a todos la mayor serenidad y confianza [...]".

Felipe Vl; "Estamos viviendo momentos muy graves para nuestra vida democrática. $Y$ en estas circunstancias, quiero dirigirme directamente a todos los españoles."

Aunque la raíz de la intervención pública de ambos jefes de Estado versa por motivos diferentes, por un lado, un golpe de Estado, y, por otro lado, la 
proclamación unilateral e ilegal de la independencia de Cataluña. Ambos monarcas reiteraron mantener su firme compromiso con el orden constitucional y la legalidad vigente con el consiguiente llamamiento a las autoridades públicas y a los ciudadanos a respetar el orden y el compromiso.

Juan Carlos I; "Ante la situación creada por los sucesos desarrollados [...], confirmo que he ordenado a las Autoridades Civiles y a la Junta de jefes de Estado Mayor que tomen todas las medidas necesarias para mantener el orden constitucional dentro de la legalidad vigente."

Felipe VI; "[...] es responsabilidad de los legítimos poderes del Estado asegurar el orden constitucional y el normal funcionamiento de las instituciones, la vigencia del Estado de Derecho y el autogobierno de Cataluña, basado en la Constitución y en su Estatuto de Autonomía."

En virtud de sus palabras y actos, ambos jefes de Estado, llamaron a la calma y a la mayor serenidad y confianza a todos los españoles. Con el estado de derecho y la constitución recalcaron ambos que se tomarían las medidas oportunas, frente a aquellos actos que estaban al margen de la legalidad y los derechos de millones de españoles.

Juan Carlos I; "[...] pido a todos la mayor serenidad y confianza y les hago saber que he cursado a los Capitanes Generales de las Regiones Militares, Zonas Marítimas y Regiones Aéreas [...]".

[...] no puede tolerar en forma alguna acciones o actitudes de personas que pretendan interrumpir por la fuerza el proceso democrático $[\ldots]$ ".

Felipe VI "[...] vivimos en un Estado democrático que ofrece las vías constitucionales para que cualquier persona pueda defender sus ideas dentro del respeto a la ley. Porque, como todos sabemos, sin ese respeto no hay convivencia democrática posible en paz y libertad, ni en Cataluña, ni en el resto de España [...]”. 
Y al conjunto de los españoles, que viven con desasosiego y tristeza estos acontecimientos, les transmito un mensaje de tranquilidad, de confianza y, también, de esperanza."

Por último, ambos resaltaron y recordaron la importancia y el papel de la Corona como símbolo de unidad nacional y subrayaron su compromiso con la constitución y la defensa de ésta frente a las amenazas que supongan vulnerar la constitución y la convivencia de la sociedad española.

Juan Carlos I; "La Corona, símbolo de la permanencia y unidad de la patria, no puede tolerar en forma alguna acciones o actitudes de personas que pretendan interrumpir por la fuerza el proceso democrático que la Constitución votada por el pueblo español determinó en su día a través de referéndum".

Felipe VI; “[...] el firme compromiso de la Corona con la Constitución y con la democracia, mi entrega al entendimiento y la concordia entre españoles, y mi compromiso como Rey con la unidad y la permanencia de España."

El resultado de ambos discursos guarda contenidos parejos acerca de qué cabe y qué no cabe en un sistema democrático de derecho donde encuentra su pilar y razón de ser en la Constitución de 1978. De ahí, la firmeza de las palabras de dos monarcas, de diferentes tiempos, de padre a hijo, con el compromiso y el objetivo del prevalecimiento de la ley y la constitución bajo el pilar de la monarquía en defensa de las libertades de todos los españoles frente a quienes pretenden acabar con ello fuera de la legalidad.

La intervención del discurso de Felipe VI en defensa del orden constitucional y de los poderes del estado obtuvo un gran respaldo por parte de los españoles, de los partidos políticos y amplio apoyo por todos los medios de comunicación nacionales. Por otro lado, no fue bien recibido en algunos sectores catalanes. Felipe VI supo arrojar un discurso valiente y contundente en el que destacó que la unidad de la nación y su constitución no es negociable reafirmando una vez más el compromiso del rey con la constitución y con todos los españoles. 
Felipe VI, con sus palabras y sus actos, se consolidó como rey de todos los españoles, reforzó su legitimidad como monarca y reafirmó el deber y compromiso de la Corona como base para la estabilidad y unión de España. Para los españoles se alzó un rey que carga sobre sus hombros la tarea de defender y preservar la continuidad de una democracia y una nación histórica como lo es España. Felipe VI, que había sufrido desplantes por parte de las autoridades catalanas en actos oficiales, su intervención supuso que se revitalizase a la Corona y la monarquía con el objetivo final de que la institución vela y velará por la defensa de la constitución junto con el compromiso de asegurar y promover el cumplimiento del Estado de Derecho por parte de los poderes públicos y de los propios españoles dado que la monarquía no es solo para unos pocos, sino que es para todos los españoles como ya afirmó en su Felipe VI en su proclamación como rey.

Justo en este año, el 23 de febrero de 2021, se cumplió el 40 aniversario del intento del Golpe de Estado de 1981. Felipe VI destacó en su discurso la labor que realizó su padre, la Corona y los líderes políticos para defender la constitución, además de interpelar a los ciudadanos para la defensa de la democracia (como un bien frágil que hay que cuidar y proteger), las libertades y el orden constitucional constituyen tarea de todos los españoles. Además, destacó el agradecimiento a las generaciones que hicieron posible tal logro basado en el respeto, la convivencia y el objetivo de hacer de España una gran nación.

\subsection{SENTENCIA SOBRE EL JUICIO DEL PROCÉS; SEDICIÓN O REBELIÓN}

Como resultado de las actuaciones de los líderes políticos del Gobierno de la Generalitat en 2017, fueron llamados a los tribunales para enjuiciar sus actos puesto que vulneraron la ley y la constitución. Por su condición de diputados fueron enjuiciados por la Sala de lo Penal del Tribunal Supremo, así lo estableció la propia sentencia; "[...] Esa proclamación determina, como inmediata consecuencia, la aplicación del art. 71.3 de la Constitución Española, que atribuye a la Sala Penal del 
Tribunal Supremo la competencia para conocer de los delitos imputados a los Diputados y Senadores. [...]"

El juicio fue retransmitido a través de los medios de comunicación dada su especial trascendencia tanto a nivel nacional como internacional. Para garantizar la máxima imparcialidad y las garantías de un juicio justo en virtud de la ley, acudieron observadores internacionales para realizar un seguimiento del juicio del "procés" junto con la consiguiente reproducción por internet y televisión del juicio.

En 2019 se publicó la sentencia №459/2019 de la Sala de lo Penal del Tribunal Supremo derivada de la causa especial №20907/2017 que dio lugar a varias penas y varios encarcelados por los delitos de; Sedición, malversación, y desobediencia.

Un caso paradigmático que se ha ido reiterando a lo largo del juicio, merece destacar las continuas protestas por el mismo y la negación de los propios líderes enjuiciados a la justicia española. Sin embargo, y resulta contraproducente, vistas las posiciones de los independentistas, a pesar de negar la jurisdicción española y el objeto propio del juicio, reconocieron y se sometieron al aparato legal de España y a sus órganos jurisdiccionales reconociéndolos como plenamente válidos, como país y como ley a cumplir al haberse sometido plenamente a la jurisdicción española, y por ende, a las penas que acompañan la sentencia.

Se acusaban a los dirigentes políticos por el delito de sedición por la proclamación unilateral de la independencia de Cataluña, por la convocatoria ilegal de un referéndum... y así lo menciona la sentencia;

“[...] La construcción de una república independiente exige la alteración forzada del sujeto de la soberanía, es decir, la anticipada mutilación del sujeto originario del poder constituyente, que expresa la base sociológica de cualquier Estado civilizado. El «derecho a decidir» solo puede construirse entonces a partir de un permanente desafío político que, valiéndose de vías de hecho, ataca 
una y otra vez la esencia del pacto constitucional y, con él, de la convivencia democrática."

Recalca el TS la deriva del desafío, la propia alteración de la constitución y la convivencia democrática agravaría en la "ciudadanía la falsa creencia de que el ordenamiento jurídico respalda la viabilidad de una pretensión inalcanzable. [...]" . Y es tajante al establecer que "el derecho a decidir" no es más que una consigna o conjura de marketing mediático que no encuentra ningún tipo de fundamento o respaldo normativo ni nivel nacional ni internacional siendo solo una construcción política falsa para intentar legitimar lo que se encuentra al margen de la ley.

"La Sala no puede aceptar, desde luego, el «derecho a decidir» como termómetro de medición de la calidad democrática de una sociedad. Es más, la calidad democrática de un Estado no puede hacerse depender de la incondicional aceptación de ese derecho. [...]. No existe ninguna constitución europea que avale el «derecho a decidir», tal y como de forma reiterada, reivindican los procesados. Ningún tribunal constitucional de nuestro entorno ha reconocido ese derecho entre el catálogo de derechos que forman nuestro patrimonio jurídico."

Públicamente, se suman las voces tanto de juristas como de los medios de comunicación y la opinión pública que han comentado la no calificación de la realización de un delito de rebelión por parte del tribunal siendo el resultado una condena por delito de sedición. Ello, encuentra su respuesta en la propia sentencia, ambos delitos se regulan en el código penal, y la diferencia radica en que el delito de sedición, artículo $544 \mathrm{CP}$, está caracterizado por el acto o sucesivos actos en los que se produce un alzamiento público y colectivo contra las autoridades constitucionalmente establecidas en virtud de la ley, contra el propio orden público e incluso contra la propia disciplina militar con el fin de alterar el orden democrático establecido como sucedió en Cataluña, al llamar a la ciudadanía a desobedecer las resoluciones judiciales y las del tribunal constitucional con el consiguiente desafío a las autoridades públicas plenamente constituidas a la propia constitución dando como resultado la aprobación de leyes de manera ilegal, el desacato de las 
autoridades del gobierno de la Generalitat y el consiguiente desvío de fondos públicos para dar pie a la consecución del objetivo de declarar ilegalmente y unilateralmente la independencia de Cataluña. Así lo determinó la sentencia;

"[...] Más allá de la mera actuación en grupo, la sedición exige como medio comisivo el alzamiento tumultuario y tiene la finalidad de derogar de hecho la efectividad de leyes o el cumplimiento de órdenes o resoluciones de funcionarios en el ejercicio legítimo de sus funciones. No faltan propuestas doctrinales que propugnan una interpretación actualizada de ese alzamiento público, que abarque la interconexión, de miles de personas que pueden actuar de forma convergente, sin presencia física, a través de cualquiera de los medios que ofrece la actual sociedad de la información."

Respecto a la rebelión, artículo 472 del Código Penal, el detalle de la sentencia radica en el aspecto de "la violencia" como característica esencial y conducta típica al respecto. Aunque se produjeron acciones violentas contras las propias autoridades y el asalto a edificios públicos con los consiguientes escraches o caceroladas (violencia psíquica), el tribunal consideró que; "Pero no basta la constatación de indiscutibles episodios de violencia para proclamar que los hechos integran un delito de rebelión. [...] La violencia tiene que ser una violencia instrumental, funcional, preordenada de forma directa, sin pasos intermedios, a los fines que animan la acción de los rebeldes."

Sin embargo, el tribunal desestimó la petición del Ministerio Fiscal puesto que no se dan los presupuestos de una violencia exacerbada e instrumentalizada con la consiguiente orden para perpetrar tales actos, además de la pronta actuación del propio tribunal constitucional para dar por inválidas las leyes que había aprobado el parlamento de Cataluña para poder declarar la independencia, así lo remitía la sentencia; "Bastó una decisión del Tribunal Constitucional para despojar de inmediata ejecutividad a los instrumentos jurídicos que se pretendían hacer efectivos por los acusados. [...]". 
El resultado se basó en los parámetros explicados por el propio tribunal al no producirse esa violencia instrumental, de carácter ordenado con la consiguiente probabilidad de la consecución del fin que perseguía con la secesión, el tribunal se decantó por la sedición.

\section{CONCLUSIONES Y RESULTADOS}

A continuación, se desprenden los resultados de la investigación realizada conforme a los parámetros metodológicos empleados en lo relativo a la utilidad y a las funciones que tiene encomendadas la Corona en España, así como su papel en el cumplimiento y prevalecimiento de la constitución de nuestro país y a nivel internacional como jefe de estado.

El presente artículo, tiene como finalidad proporcionar la suficiente notoriedad a la Corona y al rey Felipe VI en virtud de la labor realizada por el monarca durante estos últimos años con el objetivo de acercar al ciudadano la utilidad y la necesidad de la misma. Lejos de figurar un rey en un papel como una mera referencia en la constitución resulta imprescindible recalcar su labor que realiza junto con la casa real en beneficio del estado, como en la defensa de sus intereses en el extranjero.

Tras analizar las intervenciones públicas de Felipe VI, su labor y compromiso institucional en el marco que tiene encomendado durante estos últimos 6 años se concluye que;

La monarquía como forma política del Estado consolida la estabilidad y permanencia de la constitución y la existencia misma de España siendo coherente con su historia y con sus homólogos europeos además de lograr alcanzar los estándares más altos de calidad democrática y bienestar social. Una muestra de ello, viene reflejado en el informe que realiza Democracy Index por la Economist Intelligence Unit (EIU) de The Economist que determinan en virtud de diversos rangos como la pluralidad, cultura y participación política, funcionamiento del 
gobierno, derechos civiles entre otros, el nivel de las democracias del mundo, situando al Reino de España entre las 20 mejores democracias plenas del mundo con un ratio de puntuación de 8.08, mientras que en Europa se sitúa en el puesto 14 con el mismo ratio de puntuación. Además, se encuentran dentro de las 20 mejores democracias del mundo destacan la presencia de las monarquías entre ellas.

Felipe VI se configura como un rey que no forma parte de los tres poderes del estado, pero se encuentra vinculado a los tres, convirtiéndose en el pilar de todos ellos como jefe de estado.

Felipe VI pretende que la Corona englobe a todos los españoles sin que excluya a una parte de la sociedad, evitando que sea apropiada por los bloques políticos en una sociedad cada vez más polarizada pudiendo tener como resultado el caer en la irrelevancia por los tirones políticos e incluso ser víctima de la manipulación por unos y otros. Si esa política de desgaste persistiese en el tiempo reduciendo las funciones regias y su presencia en actos institucionales y politizados tendría como consecuencia presentar a la monarquía como innecesaria.

La labor apartidista y moderadora que ejerce ayuda al desempeño y el correcto funcionamiento de las instituciones públicas interviniendo como moderador para su correcto desarrollo puesto que la monarquía es un instrumento del Estado no un fin en sí mismo. Desafiar la monarquía parlamentaria como forma política del estado tendría como consecuencia atacar el sistema institucional y constitucional.

Los resultados de Rule of Law index 2020 apoyan la labor encomendada a los monarcas europeos y realiza un examen de la calidad de la democracia de cada país. El estudio toma varios factores como las limitaciones a los poderes gubernamentales, la corrupción, los derechos fundamentales, el orden y la seguridad la aplicación de las normas, entre otros. España se sitúa en el ranking global en el puesto 19 de 128 países. De nuevo, el informe refleja el liderato del mismo corresponde a las monarquías, las cuales tiene amplia presencia hasta el 
puesto 20, siendo la mitad monarquías, siendo plenamente respaldada la gestión, utilidad y labor realizadas por los monarcas de estos países.

Los mensajes emitidos por Felipe VI revalidan su legitimidad y apelan a toda la ciudadanía española para transmitir el mensaje constitucional, económico y social. De ello deriva, la evolución de los mensajes reales y las intervenciones públicas e internacionales se hace latente, desde Don Juan Carlos I hasta Felipe VI, debido a los cambios y demandas sociales, políticos y económicos. Como resultado de ello, los actos del rey, como jefe del Estado y embajador de la marca España, se configuran y forman parte de la política del Estado en beneficio y defensa de los intereses de España.

El relevo generacional de la monarquía consagra la renovación de la institución con Felipe VI frente a los cambios globales y nacionales a los que se enfrenta España y con un rey ampliamente preparado para desempeñar las funciones de jefe de estado. Un rey que reforma sin destruir para innovar y construir. Felipe VI, como jefe del Estado y monarca plenamente constituido, asumió sobre sí la tarea de liderar a España frente a los desafíos territoriales y constitucionales que surgían en España dando respuesta a éstos de manera clara, contundente y desde la legalidad para la tranquilidad y serenidad de todos los españoles.

Otra característica esencial es la comunicación entre los partidos políticos y su entendimiento. Felipe VI tiene encomendada la labor de colaborar continuamente para acercar más la magistratura del estado y fortalecer así la Corona ante los partidos políticos como a los ciudadanos en base a la ejemplaridad del monarca y el correcto desarrollo de sus funciones. Todo ello, otorga al mensaje real un cauce alternativo de comunicación institucional que pueda alcanzar tanto a políticos como a ciudadanos en el cumplimiento de los objetivos constitucionales, en el cual las funciones desempeñadas por el monarca repercutan en la sociedad para garantizar y fortalecer el respeto, la confianza y la credibilidad en la institución. 


\section{Figura 2}

Valoración del papel desempeñado por el Rey Felipe VI en los diferentes ámbitos

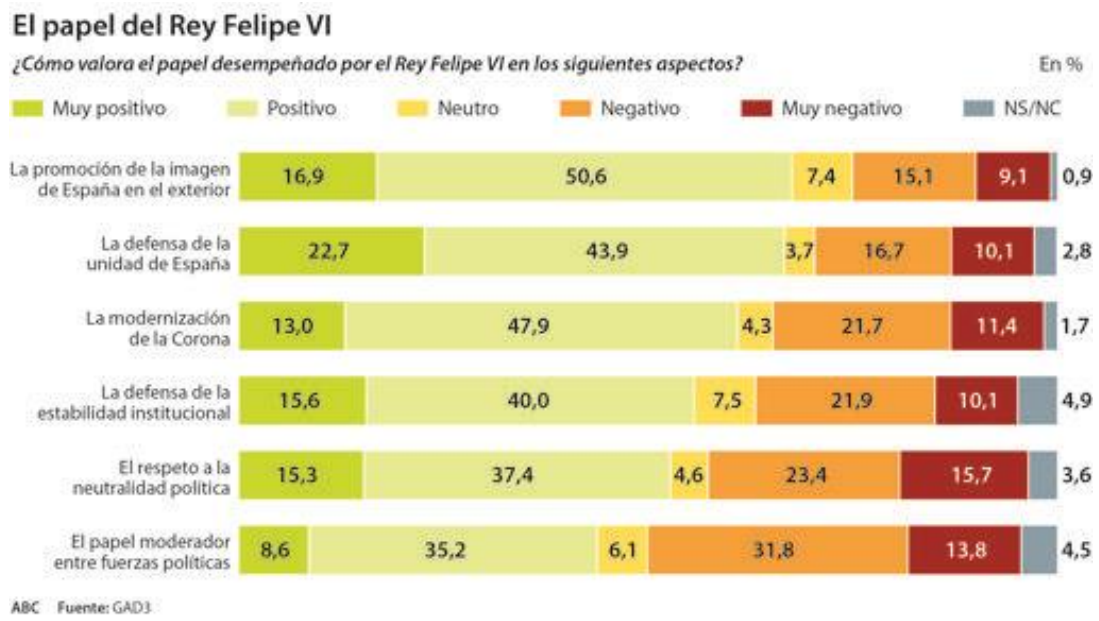

Nota. El gráfico representa una comparativa de las distintas valoraciones otorgadas por los ciudadanos a la gestión de Felipe VI en diferentes ámbitos. Recuperado de GAD3.

Los resultados demuestran que Felipe VI, mediante sus actos y el poder de su palabra se ha consolidado como referente a través de la monarquía garantizando el cumplimiento de la constitución y reafirmando en gran medida a la Corona como elemento estabilizador tanto de la nación como de las instituciones.

Como consecuencia de los resultados, Felipe VI tiene la capacidad para asentar su reinado como un modelo de funcionamiento parlamentario constitucional en el siglo XXI. Partiendo de la base del respaldo y la legitimidad de la Corona otorgada por constitución (asentada sobre la ley para actuar a través de la ley) y el consenso social.

Felipe VI y la Monarquía, ostentan el apoyo de la ley y del propio congreso desde su investidura, configurando la institución y al monarca como pilar firme y sólido de una democracia y un país que se ha encontrado en medio de 
incertidumbres, crisis económicas, la pandemia, falta de empleo, de oportunidades y mala gestión de la mano de políticos e incluso instituciones públicas. Por ello, la monarquía de Felipe VI se ha postulado al frente de la nación como jefe del estado, reafirmando su compromiso con la Corona y con la voluntad de servir a los españoles convirtiéndose así en un referente nacional para evitar y encauzar las pretensiones rupturistas, de división y malestar, transformando esa desconfianza de los ciudadanos en esperanza para la estabilidad del país.

De ahí que, se haya situado a la monarquía parlamentaria de Felipe VI como un modelo de solución democrática en el Siglo XXI. Los cambios unidos a los avances del mundo han derivado en una monarquía en constante cambio con la capacidad suficiente para adaptarse a las nuevas exigencias de la actualidad y a la que deberá dar respuesta la Corona y el jefe de estado como baluarte y garante de la estabilidad y el cumplimiento de la constitución.

Como consecuencia, la monarquía al consagrarse como un modelo parlamentario, ha situado a la figura del rey en un límite fijado en la constitución al que debe ceñirse, siendo sus actos refrendados por el gobierno y sus deberes constituidos por la ley, con el objetivo de aportar la estabilidad a los poderes del estado y velar por la defensa y el cumplimiento de la constitución. Además, incrementa el valor y la utilidad de la institución los valores inherentes que acompañan a la monarquía como el compromiso, la lealtad, la entrega de toda una vida al servicio de un bien mayor, España, la constitución y sus ciudadanos. De ahí que Felipe $\mathrm{VI}$ y su figura se moldeen constantemente, y en especial en los periodos de dificultad que están marcando su reinado, por garantizar la confianza, la credibilidad y el respecto de la institución que encarna.

En base a la investigación realizada y la utilidad práctica de la monarquía, resulta complicado aportar una solución mejor y más eficaz que la monarquía a la vista de las actuaciones del monarca y su labor realizada en el cumplimiento de la constitución acarreando el orden y la estabilidad política e institucional intercediendo y moderando con los poderes del estado para su correcto funcionamiento. 
Respecto al ámbito promotor y embajador de la marca España, mantiene constantes reuniones con representantes de todos los ámbitos culturales, empresariales, etc., para promover y potenciar como jefe de estado el producto español haciendo un llamamiento a la colaboración en la conclusión de contratos con empresas españolas en el extranjero, junto con la inversión en tecnología, económica, la contribución de España en organismos internacionales, etc.

En definitiva, Felipe VI ha consolidado el relevo generacional de una nueva España, una monarquía moderna, más exigente, más transparente y con una mayor profesionalización de sus servicios, para dirigir a una nueva generación y dar solución a las nuevas exigencias de ésta configurando así una monarquía actual para el siglo XXI. Ello, es el resultado de las palabras de Felipe VI en su Coronación, que quería ser el rey de todos los españoles.

\section{BIBLIOGRAFÍA}

\section{FUENTES DOCUMENTALES}

AREILZA, J.M.: Diario de un ministro de la Monarquía. Planeta. Barcelona. 1977.

DE VILALLONGA, J.L.: El Rey. Conversaciones con Juan Carlos I de España. Plaza \& Janes. Barcelona. 1993.

ESPINOSA DE LOS MONTEROS, L.: Los mensajes del Rey en la Pascua Militar (1976-2016). El poder de la palabra real. Fundación Universitaria Española. Madrid. 2020.

ARAGÓN REYES, M.: Dos estudios sobre la monarquía parlamentaria en la Constitución Española. Cuadernos Civitas. Madrid. 1990.

ZARZALEJOS, J.A.: Felipe VI: Un Rey en la Adversidad. Planeta. Barcelona. 2021. 
ANDERSEN, E.: Índice de Estado de derecho. World Justice Proyect. Washington. 2020.

\section{ARTículos}

ABC.ES (06-08-2018). El Rey logra la mejor valoración de la Monarquía desde la Restauración. (En Línea) Consultado el 12 de junio de 2021 en: https://www.abc.es/espana/abci-logra-mejor-valoracion-monarquia-desderestauracion-201808052317_noticia.html

EL ORDEN MUNDIAL.COM (21-07-2020). ¿Cuánto cuestan las monarquías europeas? (En línea) Consultado el 23 de junio de 2020 en: https://elordenmundial.com/mapas/coste-monarquias-europeas/

EL PAÍS.ES (13-03-1986). El Referéndum sobre la OTAN: El 'sí' vence en 13 Autonomías y 43 Provincias. (En Línea) Consultado el 12 de diciembre de 2020 en: El 'sí' vence en 13 autonomías y 43 provincias |España | EL PAís (elpais.com)

LA RAZÓN.ES (13-03-2019). Pérez-Reverte: "Si perdemos nuestra memoria, perdemos España". (En Línea) Consultado el 09 de diciembre de 2020 en: https://www.larazon.es/cultura/perez-reverte-la-historia-de-espana-es-amargapero-a-veces-tiene-luz-AL22384985/

REAL INSTITUTO ELCANO.ORG (03/2019-24/01/2019). González, C.: La calidad de la democracia española. (En línea) Consultado el 13 de junio de 2021 en: http://www.realinstitutoelcano.org/wps/portal/rielcano_es/contenido?WCM_GLOBA L_CONTEXT=/elcano/elcano_es/observatoriomarcaespana/comentariogonzalezenriquez-calidad-democracia-espana

\section{FUENTES DOCTRINALES}

CONGRESO.ES "Referéndum sobre el Proyecto de Ley para la Reforma Política - Constitución Española” (1976). Consultado el 15 de diciembre de 2020 en: https://app.congreso.es/consti/elecciones/referendos/ref_r_p.htm 
CONGRESO.ES "Referéndum sobre el Proyecto de Constitución Constitución Española" (1978) [Tabla]. Consultado el 20 de julio de 2021 en: https://app.congreso.es/consti/elecciones/referendos/ref_consti.htm

CONGRESO.ES. (2014, 17 de junio). "Las Cortes Generales aprueban el proyecto de Ley Orgánica de abdicación de S.M. el Rey don Juan Carlos” (2014). Consultado el 13 de junio de 2021 en: https://www.congreso.es/web/guest/notas-de prensa?p_p_id=notasprensa\&p_p_lifecycle $=0 \& p \_p \_s t a t e=$ normal\&p_p_mode $=v i e$ w\&_notasprensa_mvcPath=detalle\&_notasprensa_notald=13146

CONGRESO.ES "Sinopsis artículo 56 - Constitución Española” (1976). Consultado el 15 de febrero de 2021 en: https://app.congreso.es/consti/constitucion/indice/sinopsis/sinopsis.jsp?art=56\&tipo $=2$

CONGRESO.ES “Sinopsis artículo 58 - Constitución Española” (1976). Consultado el 16 de febrero de 2021 en:

https://app.congreso.es/consti/constitucion/indice/sinopsis/sinopsis.jsp?art =58\&tipo=2\#: :text=\%2D\%20Se\%20consagra\%20por\%20la\%20Constituci\%C3\% B3n,a\%20su\%20\%C3\%A1mbito\%20de\%20competencias

CONGRESO.ES "Sinopsis artículo 59 - Constitución Española” (1976). Consultado el 16 de febrero de 2021 en: https://app.congreso.es/consti/constitucion/indice/sinopsis/sinopsis.jsp?art=59\&tipo $=2$

CONGRESO.ES "Sinopsis artículo 62 - Constitución Española” (1976). Consultado el 17 de febrero de 2021 en: https://app.congreso.es/consti/constitucion/indice/sinopsis/sinopsis.jsp?art=62\&tipo $=2$

CONGRESO.ES "Sinopsis artículo 64 - Constitución Española” (1976). Consultado el 19 de febrero de 2021 en: 
https://app.congreso.es/consti/constitucion/indice/sinopsis/sinopsis.jsp?art=64\&tipo $=2$

E.J. (2020). «conditio sine qua non». Enciclopedia Jurídica [Versión Electrónica]. Consultado el 15 de diciembre de 2020 en: http://www.enciclopediajuridica.com/d/sine-qua-non/sine-qua-non.htm

E.J. (2020). «derecho de gracia». Enciclopedia Jurídica [Versión Electrónica]. Consultado el 18 de febrero de 2021 en: http://www.enciclopediajuridica.com/d/derecho-de-gracia/derecho-de-gracia.htm

España. Tribunal Supremo (Sala de lo Penal). Sentencia núm. 459/2019 de 14 de octubre de 2019 (Causa Especial 20907/2017).

Real Academia Española. (s.f.). Inviolabilidad del Rey. En Diccionario Panhispánico del español jurídico. Recuperado en 12 de febrero de 2021, de https://dpej.rae.es/lema/inviolabilidad-del-rey

Real Academia Española. (s.f.). Regencia. En Diccionario de la lengua española. Recuperado en 15 de febrero de 2021, de https://dle.rae.es/regencia?m=form

\section{DISCURSOS DEL REY}

Borbón, Felipe (2014): Inicio - Actividades y Agenda - Mensaje de su Majestad el Rey en su Proclamación ante las Cortes Generales. Consultado el 13 de diciembre de 2020 en: https://www.casareal.es/ES/Actividades/Paginas/actividades_discursos_detalle.as px?data $=5359$.

Borbón, Felipe (2014): Inicio - Actividades y Agenda - Palabras De Su Alteza Real El Príncipe De Asturias y De Viana En El Acto De Entrega Del Premio Príncipe De Viana De La Cultura 2014 a Don Jesús Morrás Santamaría, "Tarsicio De Azcona". Consultado el 13 de diciembre de 2020 en: 
https://www.casareal.es/ES/Actividades/Paginas/actividades_discursos_detalle.as px?data $=5349$.

Borbón, Juan Carlos (1977). FOROREAL.NET. Discurso de S.A.R el Conde de Barcelona con ocasión de la Renuncia a sus derechos sucesorios a la Corona de España, 14 de mayo 1997. (En línea) Última fecha de consulta 17 de diciembre de 2020 en: http://www.fororeal.net/docshistoricos2.htm

Borbón, Felipe (2017): Inicio - Actividades y Agenda - Mensaje de su Majestad el Rey. Consultado el 10 de marzo de 2021 en:

https://www.casareal.es/ES/Actividades/Paginas/actividades_discursos_de talle.aspx?data $=5716$

CASA REAL (2014). Abdicación de su Majestad el Rey Juan Carlos I; y Juramento y proclamación de su Majestad el Rey Felipe VI. Consultado el 05 de noviembre de 2020 en: Actos_Abdicacion_Proclamacion.pdf (casareal.es)

\section{BOE/BOC}

B.O.E. (27 de julio de 1947). Ley de Sucesión de la Jefatura del Estado de 27 julio de 1947. №208, pp. 4438 - 4239. (Referencia: BOE-A-1947-7395).

B.O.E. (5 de enero de 1977). Ley 1/1977, para la Reforma Política de 5 de enero de 1977. №4, pp. 170 - 171. (Referencia: BOE-A-1977-165).

B.O.E. (11 de enero de 1967). Ley Orgánica del Estado 1/1967, de 10 de enero. №a, pp. 466- 477. (Referencia: BOE-A-1967-5).

B.O.E. (17 de octubre de 1977). Ley 46/1977, de 15 de octubre, de Amnistía. Na248. (Referencia: BOE-A-1977-24937).

B.O.C. (8 de noviembre de 1978). Los pactos de la Moncloa. №180, pp 3908-3941.

https://www.congreso.es/public_oficiales/L0/CONG/BOCG/BOC_180.PDF 
B.O.E. (29 de diciembre de 1978). Constitución Española. №311, pp 2931329424. (Referencia: BOE-A-1978-31229).

B.O.E. (16 de julio de 1997). Ley 24/1997, de Consolidación y Racionalización del Sistema de Seguridad Social. №169, pp 21781-21787. (Referencia: BOE-A-1997-15810).

B.O.E. (19 de junio de 2014). Ley Orgánica del Estado 3/2014, de 18 de junio. №148, pp. 46396-46398. (Referencia: BOE-A-2014-6476).

B.O.E. (31 de diciembre de 2020). Ley 11/2020, de Presupuestos Generales del Estado para el año 2021. №341, pp 125958-126732. (Referencia: BOE-A-202017339).

D.O.G.C. (06 de septiembre de 2017). Ley 19/2017, del referéndum de autodeterminación de Cataluña de 06 de septiembre de 2017. №7449A. (Referencia: DOGC-B-17249083-2017).

D.O.G.C. (08 de septiembre de 2017). Ley 20/2017, de transitoriedad jurídica y funcional de la República de 08 de septiembre de 2017. №7451A. (Referencia: DOGC-B-17251069-2017).

B.O.E. (24 de noviembre de 1995). Ley Orgánica 10/1995, de 23 de noviembre, del Código Penal. №281, pp. 33987-34058. (Referencia: BOE-A-199525444).

\section{OTRAS FUENTES}

Miguel G. [Miguel G.] (2011, septiembre 29). Juan Carlos I, proclamación en las Cortes (22-11-1975) [Vídeo Youtube]. Recuperado de https://www.youtube.com/watch?v=1RRwRSGI79M

P. E [Protocolo y Etiqueta] (2017, octubre 14). Discurso del Rey Juan Carlos I, golpe de Estado del 23 de Febrero de 1981. [Vídeo Youtube]. Recuperado de https://www.youtube.com/watch?v=4DodgdzMBkM 
